\title{
PATTERN OF CERVICAL SCREENING UTILIZATION IN ITALY
}

\author{
Monica Ferraroni,, Carlo La Vecchia, ${ }^{2,3}$ Romano Pagano,, Eva Negri, ${ }^{2,5}$ Fabio Parazzini ${ }^{2}$ and Adriano Decarli ' \\ ('Institute of Medical Statistics, University of Milan, ${ }^{2}$ «Mario Negri » Institute for Pharmacological Research, Milan, ${ }^{3}$ Institute \\ of Social and Preventive Medicine, University of Lausanne, Switzerland, ${ }^{4}$ Central Institute of Statistics, Rome, \\ and ${ }^{5}$ Inter-University Consortium for Automatic Data Processing (CILEA), Segrate, Milan)
}

The pattern of cervical screening utilization in Italy was analyzed using data from the 1986-1987 National Health Survey on the basis of a sample of 27,455 women aged 20 to 79 randomly selected within strata of municipality of residence and age in order to be representative of the whole Italian population. Overall, about $17 \%$ of women aged 20 to 79 were screened per year, for a total of 3.5 to 4 million cervical smears per year. The highest frequency was reported in younger middle age, about one in four women being screened per year in the age groups 30 to 49 , and there was a substantial decline above age 50 . Cervical smear rates were

There is consistent evidence that organized cervical cancer screening programs have a favorable impact on incidence and mortality from the disease. For instance, changes in mortality from cervical cancer in Nordic countries are clearly related to the level of screening: the fall in mortality between 1965 and 1982 was most pronounced $(-80 \%)$ in Iceland, where about $80 \%$ of the population aged 25 to 69 is compliant to an organized screening program, intermediate in Denmark, Finland and Sweden, where mass screening is restricted to younger middle age, and small in Norway $(-10 \%)$, where only $5 \%$ of the population is covered by organized programs $(7,9,10)$.

In Italy, there is no centralized program for cervical cancer screening. Nonetheless, mortality from cervical cancer has decreased substantially (over $50 \%$ ) during the last three decades (5), and at least part of the decline may be related to screening (10). We therefore considered the information on Pap smear collected in the context of the 1986-87 National Health Survey (8), in order to describe the pattern of screening in Italy in relation to known aspects of the descriptive and analytical epidemiology of cervical cancer.

\section{Material and methods}

The third National Health Survey (8) was conducted by the Central Institute of Statistics between November 1986 and April 1987, data collection being split over six months to reduce problems linked to seasonal variability. higher in Northern areas $(22 \%)$, where mortality from cervical cancer is lower, than in the Centre $(16 \%)$ and South $(11 \%)$ of the country. Further, there was a strong positive social class gradient in the utilization of cervical screening, in relation to both education and occupation. In spite of the absence of any organised mass screening program, cervical screening is a relatively common procedure among Italian women. However, this study provides further quantitative evidence of a markedly irrational utilization of non-organized cervical screening, which tends to end up selectively used by the groups in which cervical cancer is less common.

A sample of 25,427 families (for a total of 77,151 individuals) was randomly selected within strata of geographical areas (regions), size of municipality and size of the household, to be representative of the whole Italian population. Interviews were arranged and conducted by civil servants (appointed by each municipality included in the study) within the houses of the families identified. Overall participation rate was satisfactory (less than $10 \%$ of the original sample had to be replaced). Proxy interviews were permitted for members not present in the house.

Information was collected on 265 items, including sociodemographic characteristics and lifestyle habits, current health status, prevalence of chronic diseases or groups of diseases, and health service utilization during the four weeks (for outpatient procedures) or the year (for inpatient procedures) preceding the interview. Among other diagnostic or screening procedures (blood tests, urine tests, $\mathrm{x}$ rays, echography, computerised axial tomography scan), information was specifically elicited on cervical smears.

We obtained copy of the original computer tape from the Central Institute of Statistics including available information for each subject interviewed. Only women aged 20 to 79 were included in the present analyses, for a total of 27,455 subjects.

Rates of Pap smear were expressed per 100 woman/years (i.e. multiplying the recorded smear rates of the last four weeks by 13 to assess yearly compliance) and directly standardized, when appropriate, on the overall population of women aged 20 to 79 .

Acknowledgments: This work was conducted within the framework of the CNR (Italian National Research Council) Special Project « Oncology » (contract no. 85.02209.44). The contributions of the italian League Against Tumours, and of the Italian Association for Cancer Research, Milan, Italy, are gratefully acknowledged. We wish to thank Ms. Judy Baggott and the G.A. Pfeiffer Memorial Library Staff for editorial assistance.

To whom correspondence should be addressed: Dr. Monica Ferraroni, Istituto di Biometria e Statistica Medica, Via G. Venezian 1, 20133 Milano, Italy.

Received October 18, 1988. 


\section{Results}

Table 1 gives the estimated frequency of cervical smear utilization in subsequent age groups of Italian women. Overall, about $17 \%$ of women aged 20 to 79 were screened in one year. Twenty-nine percent of the smears were performed in private laboratories and directly paid by the women; over $70 \%$ were done in public structures. The highest frequency was reported in younger middle age, about one in four women being screened per year in the age group 30 to 49 , and there was a substantial decline above age 50 .

Cervical smear rates were about double in the Northern areas $(22 \%)$ compared with the South of the country $(11 \%)$, and intermediate in central areas (16\%, table 2$)$. More detailed analysis according to geographical areas showed no substantial difference in various areas of the North $(22.9 \%$ in the Nort-West vs. $21.8 \%$ in the NorthEast), or in the islands (Sardinia and Sicily, $13.1 \%$ ) vs. the other Southern regions $(10.7 \%)$. Data on a regional or provincial scale were difficult to interpret, on account of small absolute numbers in various areas.

Various socio-demographic indicators are considered in Table 3. There was a strong positive social class gradient, in relation to education and occupation. Cervical smear rates were higher in married women than in never married, and in ever (particularly) and ex smokers as compared to never smokers.

\section{Discussion}

The 1986-87 National Health Survey findings indicate that, in spite of the absence of organized mass screening programs, about one in six women aged 20 to 79 undergo a smear each year, for a total of 3.5 to 4 million smears per year. Thus, unorganized cervical screening is a relatively widespread procedure in Italy, although the percentage of women screened is substantially lower than in the United States, where about $50 \%$ of women reported a screening smear during the previous year, on the basis of National Health Interview Survey data (1).

However, cervical smear rates were substantially higher in the lower risk groups: younger women, of upper social class, and living in the Northern areas of the country, where cervical cancer rates are appreciably lower $(4,13)$. Thus, this study provides further quantitative evidence $(2-4,6,15)$ that unorganized screening tends to be selectively aimed at the groups in which cervical cancer is less common. Further, it gives information of epidemiological interest in relation to other potential risk factors for cervical cancer. For instance, the present data suggest that the elevated cervical cancer risk in smokers in Italy cannot be explained in terms of different Pap smear utilization by smokers $(11,12)$.

The present article is based on a typical, broadly oriented, national health household survey and, as such, has all the associated strengths and weaknessess.

The study sample was large and representative of the whole Italian population in terms of distribution for age and region of residence (but not necessarily for the variables directly considered in this articles). Participation rate was satisfactory, since over $90 \%$ of the original sample could be traced and interviewed. Thus, it is unlikely that the present findings are appreciably affected by selection bias,
Table 1 - Frequency of cervical smear utilization in separate age groups of Italian women. The 1986-87 Italian National Health Survey (8).

\begin{tabular}{rcc}
\hline & $\begin{array}{c}\text { Cervical smear rates } / 100 \\
\text { woman years }\end{array}$ & (SE) \\
\hline Age group & & \\
$20-29$ & 16.25 & $(1.96)$ \\
$30-39$ & 26.52 & $(2.46)$ \\
$40-49$ & 24.83 & $(2.51)$ \\
$50-59$ & 15.73 & $(2.01)$ \\
$60-69$ & 9.49 & $(1.76)$ \\
$70-79$ & 1.95 & $(0.98)$ \\
Total & 16.89 & $(0.88)$ \\
\hline
\end{tabular}

Table 2 - Frequency of cervical smear utilization in separate Italian geographical areas. The 1986-87 Italian National Health Survey (8).

\begin{tabular}{ccc}
\hline & \multicolumn{2}{c}{ Smear rates/100 woman years } \\
\cline { 2 - 3 } & Crude & Age-adjusted \\
\hline Geographical area & & \\
North & 22.01 & 22.50 \\
Center & 15.85 & 15.95 \\
South & 11.30 & 10.84 \\
\hline
\end{tabular}

1 Directly standardised for age in decades.

Table 3 - Frequency of cervical smear utilization according to selected socio-demographic indicators. The 1986-87 Italian National Health Survey (8).

\begin{tabular}{|c|c|c|}
\hline & \multicolumn{2}{|c|}{ Cervical smear rates/100 woman years } \\
\hline & Crude & Age-adjusted ' \\
\hline \multicolumn{3}{|l|}{ Completed education } \\
\hline Primary school & 10.85 & 11.02 \\
\hline Middle school & 22.30 & 19.67 \\
\hline High school or university & 25.61 & 23.24 \\
\hline \multicolumn{3}{|l|}{ Occupation } \\
\hline Professional & 32.50 & 34.98 \\
\hline Clerical or manual skilled & 25.87 & 19.03 \\
\hline Manual, unskilled & 17.57 & 13.66 \\
\hline Not occupied & 14.09 & 15.72 \\
\hline \multicolumn{3}{|l|}{ Marital status } \\
\hline Never married & 9.96 & 10.92 \\
\hline Married & 18.21 & 18.48 \\
\hline \multicolumn{3}{|l|}{ Cigarette smoking } \\
\hline Never smokers & 14.52 & 15.28 \\
\hline Ex smokers & 26.68 & 24.71 \\
\hline Current smokers & 24.96 & 22.67 \\
\hline
\end{tabular}

'Directly standardised for age in decades. 
although, since cervical smear is strongly influenced by socio-economic variables, same selection bias in favour of attenders cannot be excluded.

Likewise, since information was collected in the four weeks before the interview, recall bias should not have influenced the results, although the fact that information was based on subjects' recall only, in the absence of confirmation on medical records, is clearly an important problem in the interpretation of this dataset. The reliability, moreover, is probably poorer for proxy interviews, and the problems linked to seasonal variability are reduced, but not totally eliminated, by the fact that data collection was splitted over a six month period.

A further major limitation of this study is the small amount of information available, since data were collected only on the most recent smear. Therefore, no inference is possible on repetition, interval between smears, etc. Nonetheless, the pattern that emerged in relation to the various indicators considered is consistent enough to allow the conclusion of a markedly (if not totally) inadequate utilization of cervical screening in Italy.

However, screening may still have had some impact on the differential decline of cervical cancer mortality in various Italian geographical areas. The fall in mortality between the early and the late 1970 's, in fact, was considerably greater in Northern Italy $(-29 \%)$ than in the South $(-10 \%)$ and the geographical differences in frequencies of screening were probably one of the factors determining these different slopes in the decline (14). This observation

\section{References}

1. Anonimous: Provisional estimates from the National Health Interview Survey supplement on cancer control. United States, January-March 1987. JAMA, 260: 1206-1207, 1988.

2. Cecchini S., Grazzini G., Ciatto S.: Cervical cancer screening in Tuscany: A survey of the actual state of cervical cancer prevention in the local sanitary units of the Tuscan region. Tumori, 74: 253-256, 1988.

3. Charny M.C., Farrow S.C.: Who is using cervical cancer screening services? Health Trends, 19: 3-5, 1987.

4. Cislaghi C., Decarli A., La Vecchia C., Laverda N., Mezzanotte G., Smans M.: Dati, Indicatori e Mappe di Mortalità Tumorale. Data, Statistics and Maps on Cancer Mortality. Italia 1975-1977. Pitagora Editrice, Bologna, 1986.

5. Decarli A., La Vecchia C.: Cancer mortality in Italy, 19551978. La mortalità per tumori in Italia, 1955-1978. Tumori, 70, suppl., 529-742, 1984.

6. Draper G.J., Cook G.A.: Changing patterns of cervical cancer rates. Br. Med. J. (Clin. Res.), 287: 510-512, 1983.

7. IARC Working Group on Evaluation of Cervical Cancer Screening Programmes: Screening for squamous cervical cancer: Duration of low risk after negative results of cervical cytology and its implication for screening policies. Br. Med. J. (Clin. Res.), 293: 659-664, 1986.

8. ISTAT (Istituto Centrale di Statistica): Indagine sulle condizioni di salute della popolazione e sul ricorso ai servizi sani- gives rise to important perspectives for focusing screening programs not only on an individual, but also on a community scale.

\section{L'utilizzo dello screening cervicale in Italia}

L'utilizzo dello screening cervicale in Italia è stato analizzato sulla base dei dati della Indagine ISTAT sulle condizioni di Salute della Popolazione del 1986-87, riferita ad un campione di 27.455 donne dai 20 ai 79 anni selezionate casualmente all'interno di strati definiti dal comune di residenza e dall'età, in modo da essere rappresentativo dell'intera popolazione italiana. Nell'insieme circa il $17 \%$ delle donne dai 20 ai 79 anni si erano sottoposte a screening cervicale per anno, per un totale di 3,5-4 milioni di esami per anno. La frequenza più elevata si registrava in giovane età, con circa un test di screening ogni quattro donne tra i 30 ed i 49 anni, mentre si osservava un declino marcato al di sopra dei 50 anni. I tassi di screening cervicale erano più elevati nelle aree del Nord $(22 \%)$, dove la mortalità per tumore del collo dell'utero è più bassa, rispetto al Centro $(16 \%)$ ed al Sud $(11 \%)$. Inoltre, vi era un forte gradiente sociale positivo sia in riferimento al livello di istruzione che al tipo di occupazione. Questo studio indica che, anche in assenza di programmi organizzati, lo screening cervicale è una procedura utilizzata con relativa frequenza dalle donne italiane. Inoltre, esso fornisce stime quantitative di come questo utilizzo tenda ad essere ampiamente irrazionale, con frequenze selettivamente più elevate nei gruppi di donne in cui il carcinoma del collo dell'utero è meno diffuso.

tari. Novembre 1986 - Aprile 1987. Primi risultati. Notiziario ISTAT, 8: n. 17, 1987.

9. Laara E., Day N.E., Hakama M.: Trends in mortality from cervical cancer in the Nordic countries: Association with organised screening programmes. Lancet, 1: 1247-1249, 1987.

10. La Vecchia C., Decarli A., Gallus G.: Epidemiological data on cervical carcinoma relevant to cytopathology. Appl. Pathol., 5: 25-32, 1987.

11. La Vecchia C., Franceschi S., Decarli A., Fasoli M., Gentile A., Tognoni G.: «PAP » smear and the risk of cervical neoplasia: Quantitative estimates from a case-control study. Lancet, 2: 779-782, 1984.

12. La Vecchia C., Franceschi S., Decarli A., Fasoli M., Gentile A., Parazzini F., Regallo M.: Sexual factors, venereal diseases, and the risk of intraepithelial and invasive cervical neoplasia. Cancer, 58: 935-941, 1986.

13. La Vecchia C., Franceschi S., Decarli A., Fasoli M., Gentile A., Tognoni G.: Cigarette smoking and the risk of cervical neoplasia. Am. J. Epidemiol., 123: 22-29, 1986.

14. Mezzanotte G., Cislaghi C., Decarli A., La Vecchia C.: Cancer mortality in broad Italian geographical areas, 19751977. Tumori, 72: 145-152, 1986.

15. Parkin D.M., Collins W., Clayden A.D.: Cervical cytology screening in two Yorkshire areas: Patterns of service. Public Health, 95: 311-321, 1981. 